\title{
Specialty medical education being transformed
}

\author{
— Cite as: CMAJ 2017 June 12;189:E811. doi: 10.1503/cmaj.1095418
}

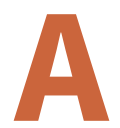
nesthesiologists, and head and neck surgeons will celebrate Canada Day by making history. On July 1 , these specialties will become the first in the country to adopt a competence by design (CBD) model for medical education.

"This is the biggest change we've made to specialty medical education in a century," says Dr. Jason Frank, director of specialty education, strategy and standards with the Royal College of Physicians and Surgeons of Canada in Ottawa. CBD was developed by the Royal College and Canada's 17 medical schools.

Over the next five years, specialist training will move away from certifying physicians based primarily on timebased rotations - a system in place for more than 100 years. Under the new model, which was actually recommended by a WHO report in 1978 and again in a Royal College report by Robert Maudsley in the 1980s, direct observation will be increased. Rather than assessing residents on their delivery of case reports, instructors will watch how physicians actually perform, says Frank.

CBD is based on an international standard called competency-based medical education. "This is an evolution," says Frank. "We hope that this produces better graduates

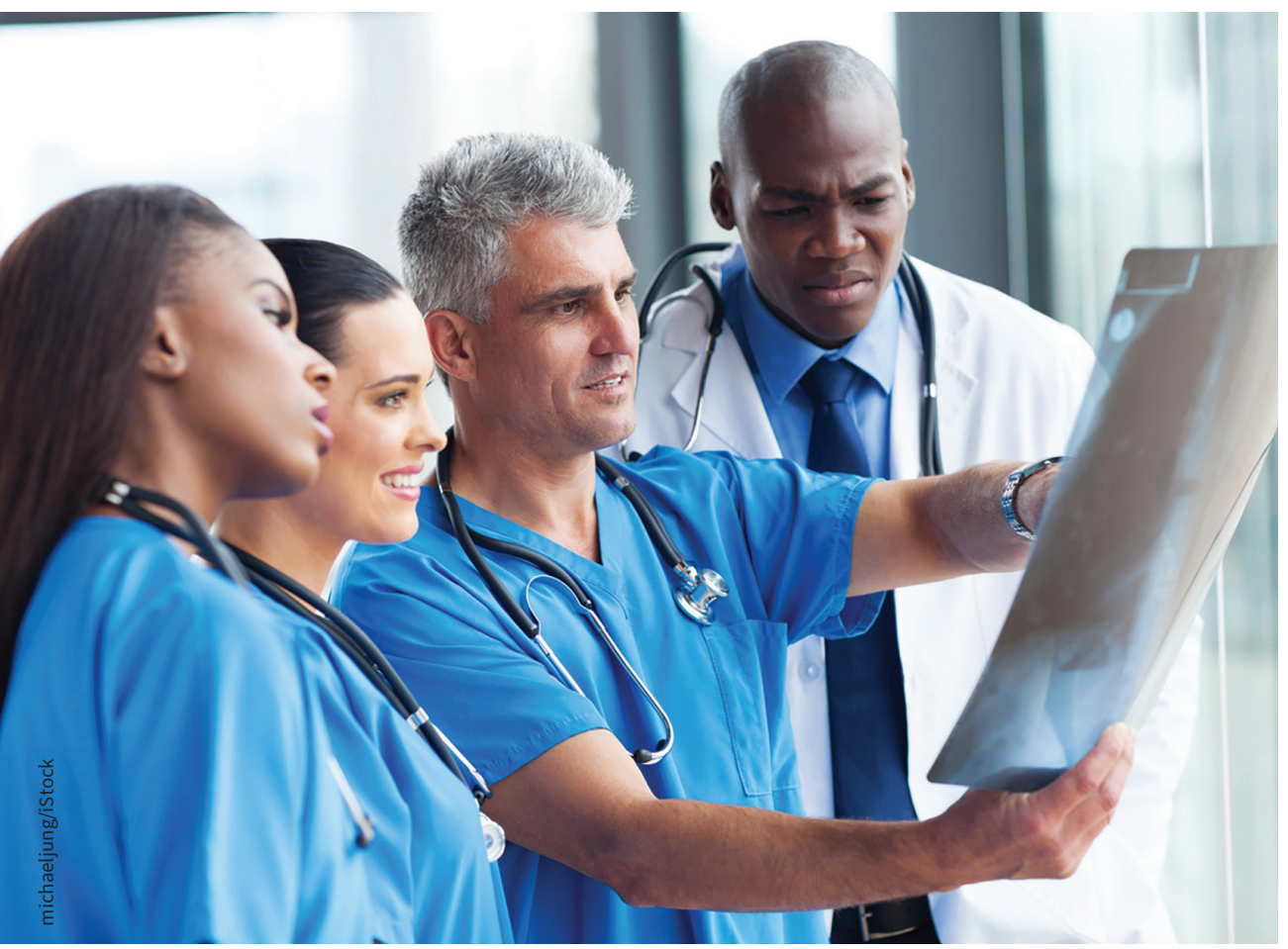

Within five years, specialty education will switch to a competence by design model.
The concept of putting in a specified number of post-graduate years to obtain certification will also be eliminated under CBD. In its place will be stages of learning; doctors will have to demonstrate that they have met the required criteria. "For the first time, the trainee does not have to complete a specific number of years of training. This is a big change," notes Frank.

$\mathrm{He}$ adds that while it is unlikely most doctors will complete their residency any earlier than under the current system, there will be greater flexibility to meet the needs of residents. "In the new system, trainees who are struggling will be identified earlier. The superstars will graduate earlier."

Other changes under the new system include moving the Royal College exams from the fourth year of training to third to allow for a period of transition to practice. And the new accreditation system will be based less on process and more on outcome.

The competence by design approach will also be applied to specialists' continuing professional development, which is tentatively slated to roll-out in 2020. Under this model, notes Frank, "[CBD] follows through your whole career."

The College of Family Physicians of Canada has already moved to a competency-based curriculum, which it calls the Triple C. The three components of the program are comprehensive education and patient care; continuity of education and patient care; and being centred in family medicine.

donalee Moulton, Halifax, NS 